\title{
HDO measurements with MIPAS
}

\author{
J. Steinwagner ${ }^{1,3}$, M. Milz ${ }^{1}$, T. von Clarmann ${ }^{1}$, N. Glatthor $^{1}$, U. Grabowski ${ }^{1}$, M. Höpfner ${ }^{1}$, G. P. Stiller ${ }^{1}$, and \\ T. Röckmann ${ }^{2,3}$ \\ ${ }^{1}$ Institute for Meteorology and Climate Research, Research Center Karlsruhe, Germany \\ ${ }^{2}$ Institute for Marine and Atmospheric Research Utrecht, The Netherlands \\ ${ }^{3}$ Max Planck Institute for Nuclear Physics, Heidelberg, Germany
}

Received: 8 December 2006 - Published in Atmos. Chem. Phys. Discuss.: 19 January 2007

Revised: 24 April 2007 - Accepted: 8 May 2007 - Published: 16 May 2007

\begin{abstract}
We have used high spectral resolution spectroscopic measurements from the MIPAS instrument on the Envisat satellite to simultaneously retrieve vertical profiles of $\mathrm{H}_{2} \mathrm{O}$ and $\mathrm{HDO}$ in the stratosphere and uppermost troposphere. Variations in the deuterium content of water are expressed in the common $\delta$ notation, where $\delta \mathrm{D}$ is the deviation of the Deuterium/Hydrogen ratio in a sample from a standard isotope ratio. A thorough error analysis of the retrievals confirms that reliable $\delta \mathrm{D}$ data can be obtained up to an altitude of $\sim 45 \mathrm{~km}$. Averaging over multiple orbits and thus over longitudes further reduces the random part of the error. The absolute total error of averaged $\delta \mathrm{D}$ is between $36 \%$ and $111 \%$. With values lower than $42 \%$ o the total random error is significantly smaller than the natural variability of $\delta \mathrm{D}$. The data compare well with previous investigations. The MIPAS measurements now provide a unique global data set of highquality $\delta \mathrm{D}$ data that will provide novel insight into the stratospheric water cycle.
\end{abstract}

\section{Introduction}

Water is the most important trace species in Earth's atmosphere and heavily influences the radiative balance of the planet. In the stratosphere, it is the main substrate from which polar stratospheric clouds are formed and thus a key contributor to polar ozone hole chemistry. Therefore, a possible significant increase in stratospheric water vapor as inferred from a combination of several observational series in the past is of concern (Rosenlof et al., 2001). However, the processes that control the input of water into the stratosphere are still under debate, and even the reliability of the reported water trend has been questioned (Füglistaler and Haynes, 2005).

Correspondence to: J. Steinwagner

(joerg@steinwagner.de)
Isotope measurements may have the potential to distinguish between different pathways of dehydration, in particular the "gradual dehydration" mechanism (Holton and Gettelmann, 2001) and the "convective overshooting" theory (Sherwood and Dessler, 2000). In addition, ice lofting has been recognized as an important process which causes water vapor in the lower stratosphere to be less depleted in the heavy isotopes than expected from a pure gas phase distillation process, where the heavy isotopologues are removed preferentially in a one-step condensation process (Moyer et al., 1996; Smith et al., 2006; Dessler and Sherwood, 2003). At least on small spatial scales these processes could be clearly distinguished by their isotope signatures in recent in situ measurements in the tropical tropopause region (Webster and Heymsfield, 2003). In the stratosphere, oxidation of methane produces water that is significantly enriched relative to the water imported from the troposphere and thus leads to a gradual isotope enrichment (Moyer et al., 1996; Johnson et al., 2001a; Zahn et al., 2006).

As water isotope data can provide important new insight into many of the large scale transport processes in the UT/LS region a global set of high accuracy data would be particularly valuable. In previous studies of water isotopes in the UT/LS (upper troposphere/lower stratosphere) region space borne (e.g. ATMOS (Rinsland et al., 1991; Irion et al., 1996), sub-millimeter receiver SMR (Lautie et al., 2003)), balloon borne (e.g. mid-infrared limb sounding spectrometer MIPAS-B (Fischer, 1993; Stowasser et al., 1999), far infrared spectrometer FIRS-2 (Johnson et al., 2001a,b)), airborne instruments (Webster and Heymsfield, 2003; Coffey et al., 2006) and sampling techniques (Pollock et al., 1980; Zahn et al., 1998; Zahn, 2001; Franz and Röckmann, 2005) have been used. The results obtained in these studies provide a solid basis for advanced analysis. However, most of these measurements do not provide long term global data sets of isotopologues and thus do not allow to study seasonal effects. Further, some of the (space borne) measurements do

Published by Copernicus Publications on behalf of the European Geosciences Union. 
Table 1. Microwindows used in the HDO measurements of MIPAS

\begin{tabular}{ccc}
\hline Microwindow & Left border $\left[\mathrm{cm}^{-1}\right]$ & Right border $\left[\mathrm{cm}^{-1}\right]$ \\
\hline 1 & 1250.2000 & 1253.1750 \\
2 & 1272.9000 & 1273.7000 \\
3 & 1286.5000 & 1288.1750 \\
4 & 1358.2250 & 1361.0500 \\
5 & 1364.5750 & 1365.9250 \\
6 & 1370.7500 & 1373.1500 \\
7 & 1410.4250 & 1413.4000 \\
8 & 1421.0500 & 1424.0250 \\
9 & 1424.1750 & 1427.1500 \\
10 & 1432.9500 & 1435.9250 \\
11 & 1449.6250 & 1452.6000 \\
12 & 1452.8500 & 1455.2500 \\
13 & 1467.6750 & 1470.6250 \\
14 & 1479.4750 & 1482.4500 \\
\hline
\end{tabular}

not penetrate the atmosphere deep enough to study processes at the tropopause and on the other side air borne measurements often do not reach far into the stratosphere. A continuous, global observation of the stratosphere and uppermost troposphere carried out by an instrument with high spectral resolution can provide a wealth of new information. In this paper we prove the feasibility of global space-borne HDO measurements with the Michelson Interferometer for Passive Atmospheric Sounding (MIPAS, Fischer et al. (2000)).

\section{MIPAS}

Space borne limb sounding instruments yield a sufficiently high vertical resolution to retrieve atmospheric profiles of trace species. Possibly the best suited instrument at present for stratospheric isotope research from space is MIPAS. MIPAS is a Fourier transform interferometer with a spectral resolution of $0.05 \mathrm{~cm}^{-1}$ (apodized with Norton-Beer "strong" apodization function; $0.035 \mathrm{~cm}^{-1}$ unapodized) designed to study the chemistry of the middle atmosphere detecting trace gases in the mid-infrared $(4-15 \mu \mathrm{m})$. The spectral resolution is given as the full width half maximum (fwhm) of the instrument line shapes. It is flown on Envisat (Environmental Satellite) on a sun-synchronous orbit (98 inclination, $101 \mathrm{~min}$ orbit period, $800 \mathrm{~km}$ orbit height). MIPAS scans the Earth limb in backward-looking viewing geometry. A complete vertical scan in the original nominal measurement mode from the top to the bottom of the atmosphere is made up of up to 17 spectral measurements ("sweeps") at $6,9,12, \ldots 42,47,52,60$ and $68 \mathrm{~km}$. The vertical step width between the sweeps is $3 \mathrm{~km}$ at lower heights and increases in the upper stratosphere.

\section{Retrieval of $\mathrm{HDO}$ and $\mathrm{H}_{2} \mathrm{O}$}

\subsection{Theory}

The processing software used to retrieve vertical HDO and $\mathrm{H}_{2} \mathrm{O}$ profiles from spectral measurements has been described by von Clarmann et al. (2003), where a constrained nonlinear least squares approach is used. All variables related to one limb scan are fitted simultaneously as suggested by Carlotti (1988). By using Tikhonov-type regularization (Tikhonov, 1963) smoothness of the profiles is the applied constraint. We use a first order difference operator. The radiative transfer through the atmosphere is modeled by the Karlsruhe Optimized and Precise Radiative Transfer Algorithm, KOPRA (Stiller, 2000). Spectroscopic data is taken from a special compilation of the HITRAN 2000 data base (Rothman et al., 2003) including a number of recent updates (Flaud et al., 2003). We use the microwindow approach to select relevant spectral regions for our observations. The definition of microwindows is done following an algorithm described by von Clarmann et al. (2003). This leads to the set of microwindows we use, shown in Table 1. An altitude dependent microwindow selection was performed using a procedure suggested by Echle et al. (2000). A final optimization was done by visual inspection of resulting modeled spectra with respect to cross influences of different species.

The scientific use of the isotope data lies in the comparison of changes in $\mathrm{HDO}$ to changes in $\mathrm{H}_{2} \mathrm{O}$, thus the ratio of the two species. Inferring a ratio of two species makes it advantageous that the retrieved profiles of which the ratio is calculated, have the same height resolutions in order to avoid the introduction of artifacts. The height resolution in the present study is computed from the full width at half maximum of the columns of the averaging kernel A (Rodgers, 2000)

$\mathbf{A}=\mathbf{G K}$

$\mathbf{K}$ is a weighting function (Jacobian) which contains the sensitivities of the spectral measurement to changes in related quantities, i.e. temperature, pressure. $\mathbf{G}$ is a gain matrix. In our retrieval approach $\mathbf{G}$ is

$\mathbf{G}=\left(\mathbf{K}^{T} \mathbf{S}_{\mathrm{y}}^{-1} \mathbf{K}+\mathbf{R}\right)^{-1} \mathbf{K}^{T} \mathbf{S}_{\mathrm{y}}^{-1}$

$\mathbf{R}$ is a regularization matrix which constrains the retrieval and $\mathbf{S}_{\mathrm{y}}$ is the covariance matrix of the measurement noise error. In our implementation a priori information is solely used to constrain the shape of the profile, not the abundances.

While a water vapor data set retrieved from MIPAS is already available (Milz et al., 2005; Raspollini et al., 2006) we have decided to jointly retrieve the volume mixing ratio (vmr) of $\mathrm{HDO}$ and $\mathrm{H}_{2} \mathrm{O}$. The joint retrieval of $\mathrm{H}_{2} \mathrm{O}$ and HDO helps to minimize mutual error propagation. As a priori knowledge we use 4 seasonal sets of water profiles divided in 6 latitude bands (tropics $0^{\circ}$ to $30^{\circ} \mathrm{N} / \mathrm{S}$, mid latitudes $30^{\circ}$ to $65^{\circ} \mathrm{N} / \mathrm{S}$ and high latitudes $65^{\circ}$ to $90^{\circ} \mathrm{N} / \mathrm{S}$ ) from the data set compiled by Remedios (1999). These profiles are also used 
as first guess profiles to start the iterative calculation process. The a priori for HDO is computed from these profiles by applying a height independent fractionation profile with values taken from the HITRAN data base (Rothman et al., 2003). Together with $\mathrm{HDO}$ and $\mathrm{H}_{2} \mathrm{O}$ we also retrieve $\mathrm{HNO}_{3}$, $\mathrm{CH}_{4}$ and $\mathrm{N}_{2} \mathrm{O}$ to capture the influence these species have in the error calculation for the retrieval. Initial guess profiles (profiles needed to start the iterative calculation scheme) for $\mathrm{HNO}_{3}, \mathrm{CH}_{4}, \mathrm{~N}_{2} \mathrm{O}$ were taken from previous analysis of the measurement under investigation. Additionally, background continuum radiation and radiance calibration offset are retrieved (see von Clarmann et al. (2003) for details). The actual temperature profile also was taken from previous MIPAS retrievals, while climatological abundance profiles are used for other interfering species, except for $\mathrm{O}_{3}$ and $\mathrm{N}_{2} \mathrm{O}_{5}$ where we also use previously retrieved profiles. For retrieval, we use spectral measurements from tangent altitudes between 12 and $68 \mathrm{~km}$. The actual tangent heights in $\mathrm{km}$ on which the spectral measurements for the representative profiles used in this work (13 January 2003 at $12^{\circ} \mathrm{N}$ and $28^{\circ} \mathrm{W}$ ) were carried out, are: 12.1., 15.1, 17.9, 20.8, 23.8, 26.8, 29.8, 32.3, 35.4, 38.4, 41.3, 46.3, 51.3, 59.4 and $67.4 \mathrm{~km}$. However, the profiles in this paper are presented only in the height range from $11 \mathrm{~km}$ to $45 \mathrm{~km}$. In this height region we considered the measurements to be of sufficient quality (i.e. with respect to cloud interference or signal to noise ratio) to match the requirements for studying isotope variability.

\section{2 $\mathrm{HDO}$ and $\mathrm{H}_{2} \mathrm{O}$ profiles}

In this paper, a thorough error analysis is carried out for a pair of representative $\mathrm{H}_{2} \mathrm{O}$ and $\mathrm{HDO}$ profiles. Figure 1a shows the according profile of water vapor. In this context that means total water, including all isotopologues. Figure 2a shows the corresponding HDO profile from the same set of measurements. The height resolution of both profiles is between $6 \mathrm{~km}$ (at $10 \mathrm{~km}$ ) and $8 \mathrm{~km}$ (at $45 \mathrm{~km}$ ) as shown in Figs. $3 \mathrm{c}$ and $\mathrm{d}$. The height resolution becomes worse with higher altitudes, due to the coarser measurement grid and the decreasing signal to noise ratio. The fact that both species are retrieved with the same vertical resolution is important when calculating the isotopic composition (see Sect. 5.2.3), and it is reflected by the nearly identical averaging kernels (Fig. 3a and $b$ ). Matching averaging kernels are achieved by appropriate choice of the respective $\mathbf{R}$-matrix in the joint retrieval of $\mathrm{HDO}$ and $\mathrm{H}_{2} \mathrm{O}$.

\section{Error assessment}

Following Rodgers (2000), the covariance matrix $\mathbf{S}_{\mathrm{t}}$ of the total error of a retrieved profile is characterized by

$\mathbf{S}_{\mathrm{t}}=\mathbf{S}_{\mathrm{n}}+\mathbf{S}_{\mathrm{p}}+\mathbf{S}_{\mathrm{s}}$

where $\mathbf{S}_{\mathrm{n}}$ is the covariance matrix of the noise error (i.e. measurement noise), $\mathbf{S}_{\mathrm{p}}$ represents the covariance of the param-

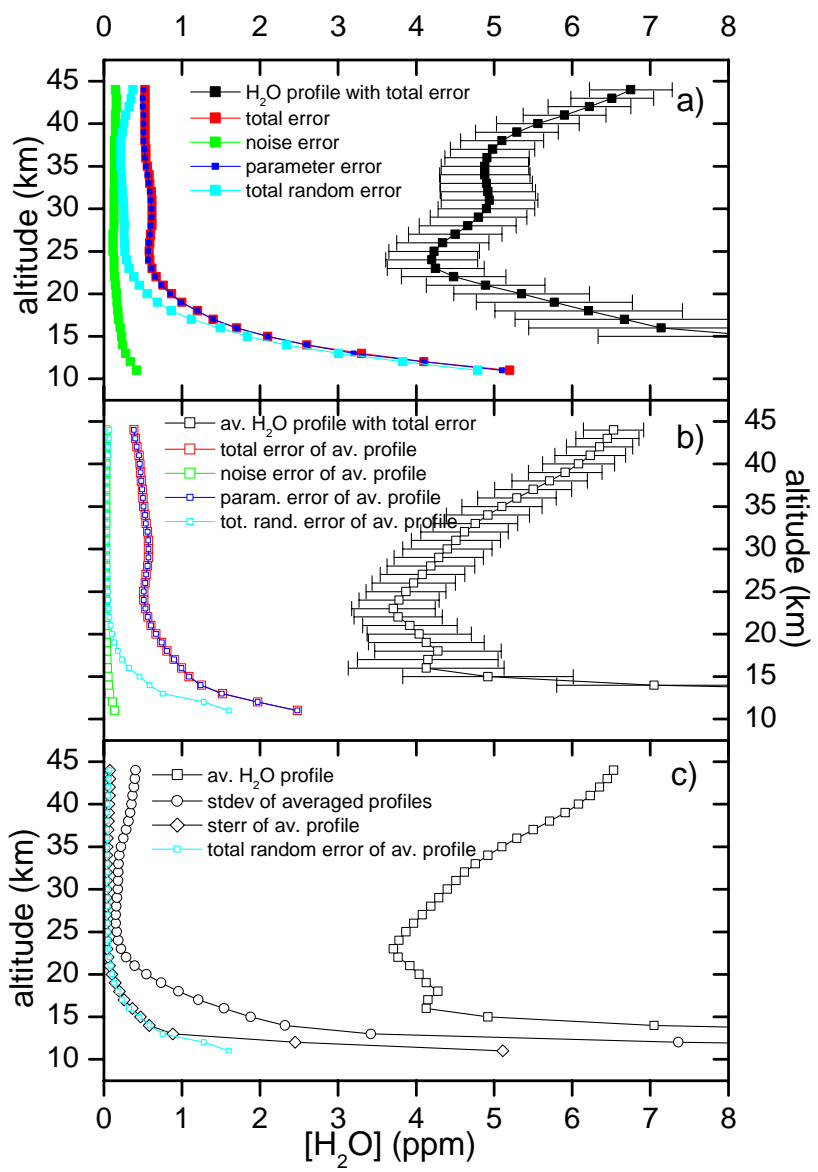

Fig. 1. (a) (top) $\mathrm{H}_{2} \mathrm{O}$ profile retrieved from MIPAS spectra measured on 13 January 2003 at $12^{\circ} \mathrm{N}$ and $28^{\circ} \mathrm{W}$ together with total error bars, noise errors, parameter errors and total random errors. (b) (middle) Zonal mean $\left(7.5^{\circ} \mathrm{N}-12.5^{\circ} \mathrm{N}\right) \mathrm{H}_{2} \mathrm{O}$ profile on $13 \mathrm{Jan}-$ uary 2003 with estimated errors. (c) (bottom) Averaged $\mathrm{H}_{2} \mathrm{O}$ profile with standard deviation ("standard deviation of averaged profiles") and standard deviation of the zonal mean profiles ("sterr of av. profile").

eter error (i.e. instrumental effects, forward modeling errors) and $\mathbf{S}_{\mathrm{s}}$ is the covariance matrix of the smoothing error. To assess and quantify the total error of our results it is necessary to discuss the covariance matrices and the related errors in the following sections in more detail.

\subsection{Noise error}

The random error due to measurement noise is calculated as

$\mathbf{S}_{\mathrm{n}}=\mathbf{G S}_{\mathrm{y}} \mathbf{G}^{T}$.

Figures 2 and 1 show that the noise error is considerably more important for $\mathrm{HDO}$ than for $\mathrm{H}_{2} \mathrm{O}$, which is expected due to the much lower abundance of HDO and the decreasing signal to noise ratio. Whereas the noise error is always 


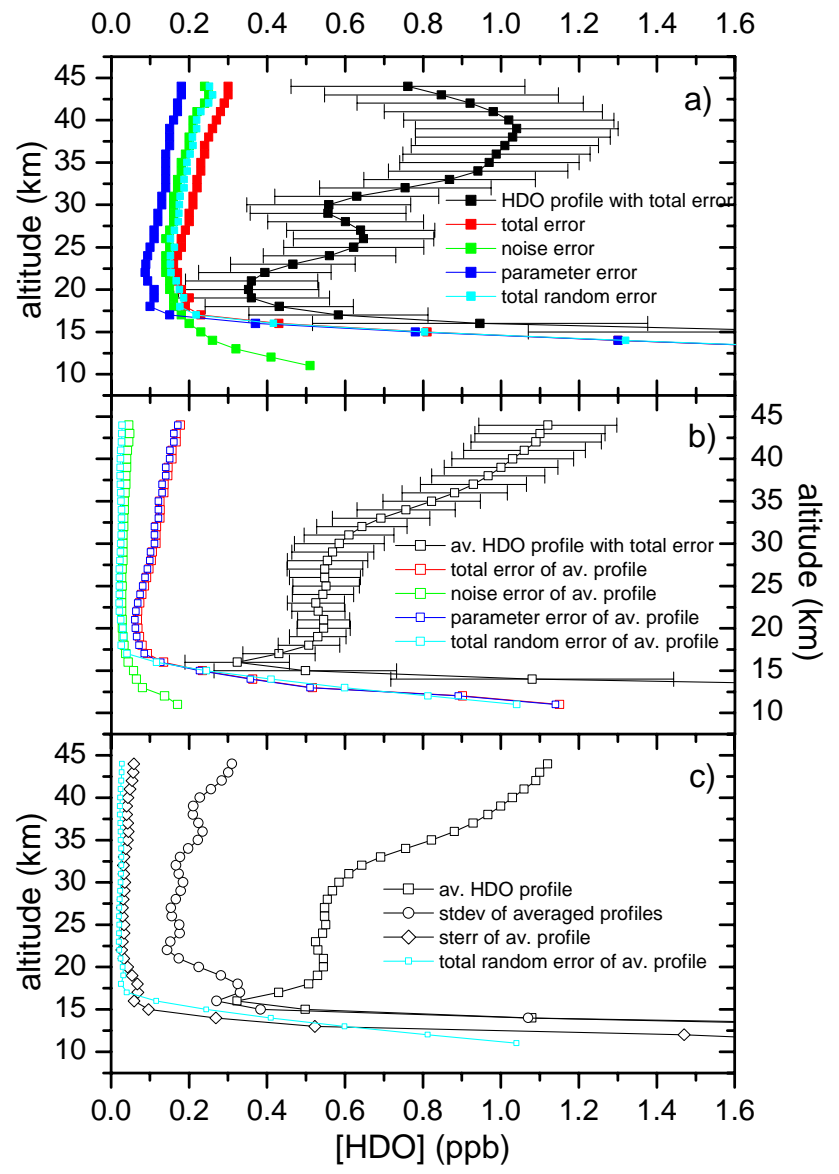

Fig. 2. (a) (top) HDO profile retrieved from MIPAS spectra measured on 13 January 2003 at $12^{\circ} \mathrm{N}$ and $28^{\circ} \mathrm{W}$ together with total error bars, noise errors, parameter errors and total random errors. (b) (middle) Zonal mean $\left(7.5^{\circ} \mathrm{N}-12.5^{\circ} \mathrm{N}\right) \mathrm{HDO}$ profile on 13 January 2003 with estimated errors. (c) (bottom) Averaged HDO profile with standard deviation and standard deviation of the zonal mean.

smaller than the parameter error for $\mathrm{H}_{2} \mathrm{O}$, noise is the dominant part of the error for HDO above $16 \mathrm{~km}$, i.e., throughout the stratosphere. Above $45 \mathrm{~km}$ noise dominates the HDO profiles and no more substantial information is retrieved.

\subsection{Parameter error}

We compute the profile errors $\sigma_{p}$ due to parameter uncertainties $\Delta \boldsymbol{b}$ as

$\sigma_{p}=\mathbf{G K}_{\mathbf{b}} \Delta b$

$\mathbf{K}_{\mathbf{b}}$ is the sensitivity of the measurements to parameter errors. For the current study the total parameter error is composed of 23 different components. The computation is done independently for the 23 contributions from additional atmospheric constituents (listed below). The four major categories of parameter errors are
Table 2. Assumed $1 \sigma$ parameter uncertainties used in the error calculation.

\begin{tabular}{ll}
\hline perturbed quantity & value and unit \\
\hline $\mathrm{SO}_{2}$ & $10-37 \mathrm{~km}: 10^{-3} \mathrm{ppm}$, above $37 \mathrm{~km} 10^{-5} \mathrm{ppm}$ \\
$\mathrm{T}$ & $2 \mathrm{~K}$ (constant over height) \\
Hor. T gradient (lat) & $0.01 \mathrm{~K} / \mathrm{km}$ (constant over height) \\
ils & $3 \%$ at 600 and $1600 \mathrm{~cm}^{-1}$ \\
los & $0.15 \mathrm{~km}$ \\
spectral shift & $0.0005 \mathrm{~cm}^{-1}$ \\
gain & $1 \%$ \\
\hline
\end{tabular}

- Influence of $1 \sigma$ uncertainties in the abundance of interfering species on the retrieval targets. The following gases are considered $\mathrm{SO}_{2}, \mathrm{CO}_{2}, \mathrm{O}_{3}, \mathrm{NO}_{2}, \mathrm{NH}_{3}$, OCS, $\mathrm{HOCl}, \mathrm{HCN}, \mathrm{H}_{2} \mathrm{O}_{2}, \mathrm{C}_{2} \mathrm{H}_{2}, \mathrm{COF}_{2}, \mathrm{CFC}-11, \mathrm{CFC}-12$, CFC-14, and $\mathrm{N}_{2} \mathrm{O}_{5}$.

- Uncertainties $(1 \sigma)$ due to temperature (tem) and horizontal temperature gradients (tgra). These uncertainties are in approximation considered random in time but are fully correlated in altitude.

- Uncertainties $(1 \sigma)$ of the instrument characterization: line of sight (los), spectral shift (shift), gain calibration (gain), instrumental line shape (ils). These systematic uncertainties are considered correlated for all species.

- Uncertainties of line intensities and pressure broadening ( $1 \sigma$ of the fwhm of the lines) in the HITRAN database for $\mathrm{HDO}$ and $\mathrm{H}_{2} \mathrm{O}$ (hitmid). These uncertainties play an important role in the error budget, especially for the error budget of the ratio of $\mathrm{HDO}$ and $\mathrm{H}_{2} \mathrm{O}$. The reason is that these uncertainties are of a systematic nature but the line strength and line intensity uncertainties of $\mathrm{HDO}$ and $\mathrm{H}_{2} \mathrm{O}$ are not correlated. This may be over pessimistic, but due to this these uncertainties will not cancel out when creating a ratio nor are they reduced when averaging.

Table 2 shows the assumed $1 \sigma$ parameter uncertainties for the most prominent error sources. Each of the following parameters has a share of the total parameter error of at least $1 \%: \mathrm{SO}_{2}$, temperature and its horizontal gradient, spectroscopic data uncertainty, line-of-sight uncertainty, spectral shift, gain calibration uncertainty and residual instrumental line shape error. Figures $4 \mathrm{a}$ and $\mathrm{b}$ show the contribution of the major parameter errors to the total parameter error for $\mathrm{HDO}$ and $\mathrm{H}_{2} \mathrm{O}$ respectively. The strongest influence on the parameter error in both cases is due to uncertainties in spectroscopic data when looking at altitudes above $17 \mathrm{~km}$. At lower altitudes the random parts of the parameter error are bigger.

The total parameter error for the HDO profile is between 0.10 and $3 \mathrm{ppb}$ (parts per billion, $10^{-9}$ ) for altitudes between 

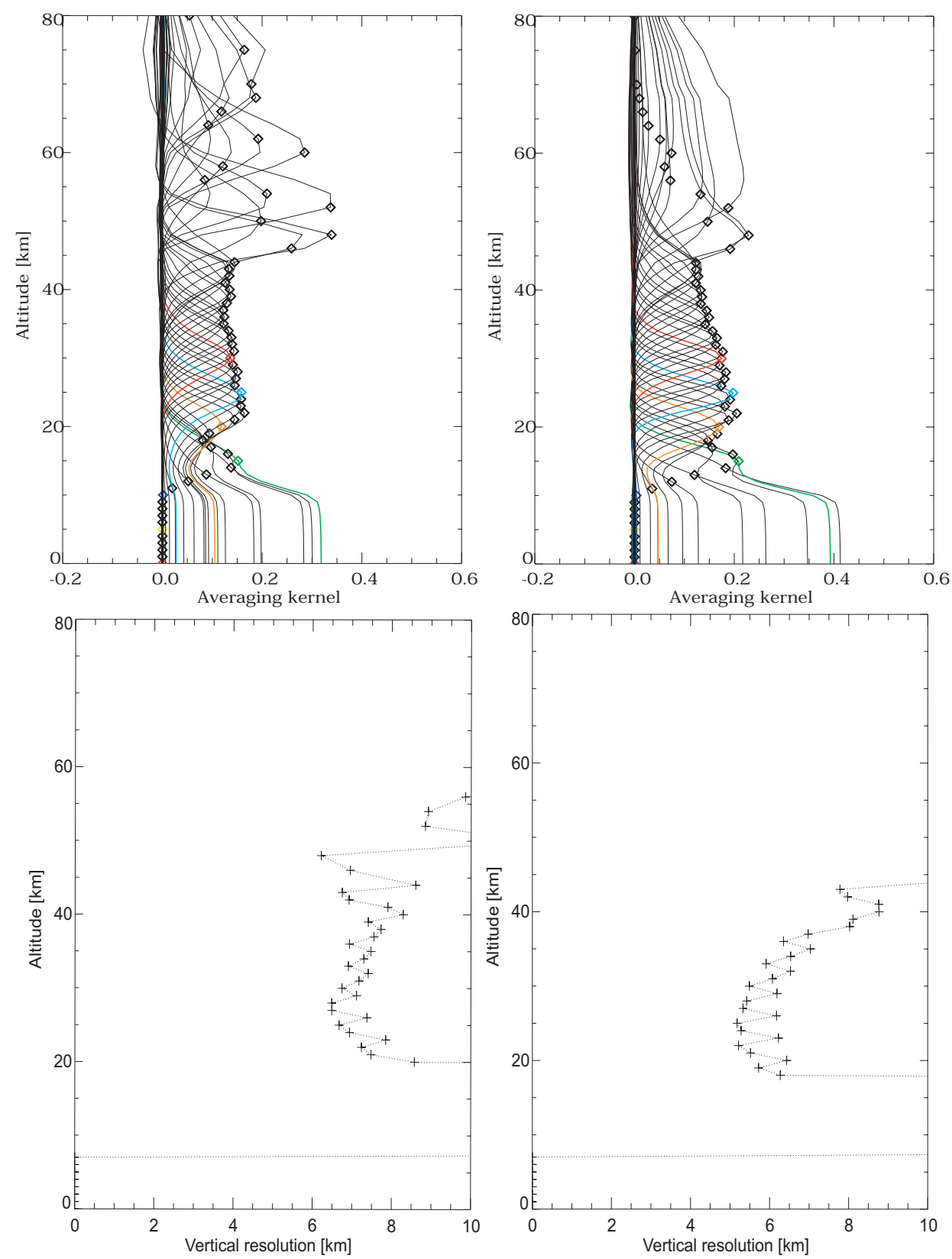

Fig. 3. (a) Columns of the averaging kernel of $\mathrm{H}_{2} \mathrm{O}$ (left) and (b) $\mathrm{HDO}$ (right). (c) Height resolution of $\mathrm{H}_{2} \mathrm{O}$ (left) and (d) $\mathrm{HDO}$ (right).

10 and $45 \mathrm{~km}$ (Fig. 2a). At most altitudes it is approximately $0.10 \mathrm{ppb}$. For $\mathrm{H}_{2} \mathrm{O}$, parameter errors are the dominating error source compared to the noise error (Fig. 1a). They are in the range between 0.5 to $5 \mathrm{ppm}$ (parts per million) for a single profile (the latter in the troposphere only). The contribution from $\mathrm{SO}_{2}$ may be over pessimistic because it is based on assumptions on the amount of $\mathrm{SO}_{2}$ in the atmosphere which were made before Envisat was launched.

\subsection{Smoothing error}

The smoothing error $\mathbf{S}_{s}$ is introduced by the limited capability of an instrument to resolve fine structures. To calculate the smoothing error it would be necessary to evaluate

$\mathbf{S}_{\mathrm{s}}=(\mathbf{A}-\mathbf{I}) \mathbf{S}_{\mathrm{e}}(\mathbf{A}-\mathbf{I})^{T}$

with I being the unity matrix. As we do not accurately know the variability of the true atmospheric state (represented by matrix $\mathbf{S}_{\mathrm{e}}$ ) we are not able to statistically evaluate the smoothing error. Instead, the effect of smoothing 

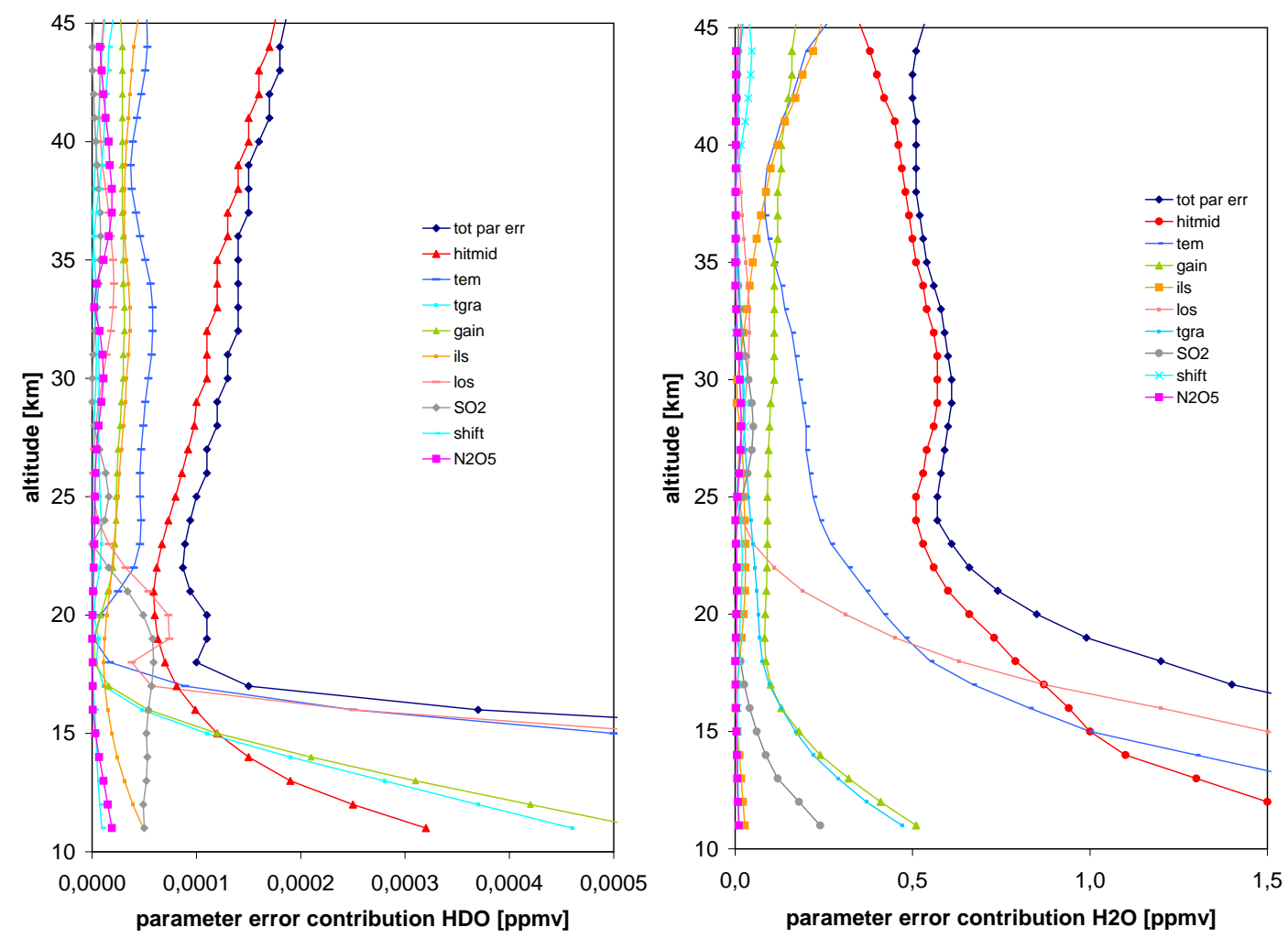

Fig. 4. Contributions of the single parameter errors to the total parameter error for (a) (left) $\mathrm{HDO}$ and (b) (right) $\mathrm{H}_{2} \mathrm{O}$.

is addressed in our sensitivity study (see Sect. 5.2.4), where we show that an artificially introduced sharp disturbance is smoothed out over a region that corresponds to the width of the averaging kernels (Fig. 3a).

\subsection{Total error}

The total error variance $\sigma_{\mathrm{t}, i}^{2}$ at altitude $i$ is calculated as

$\sigma_{\mathrm{t}, i}^{2}=\left(\mathbf{S}_{\mathrm{t}}\right)_{i, i}=\left(\mathbf{S}_{\mathrm{n}}\right)_{i, i}+\sum \sigma_{\mathrm{p}, i}^{2}$.

Figure 2 shows the total error for a typical HDO profile (red line). The total error lies between $3.30 \mathrm{ppb}$ at $11 \mathrm{~km}(6 \mathrm{~km}$ height resolution) and $0.16 \mathrm{ppb}$ at $23 \mathrm{~km}(6-7 \mathrm{~km}$ height resolution). At most altitudes above $23 \mathrm{~km}$ it does not exceed $0.30 \mathrm{ppb}$. Figure 1 shows the total error for $\mathrm{H}_{2} \mathrm{O}$. The total error is between $5.20 \mathrm{ppm}$ at $11 \mathrm{~km}(6 \mathrm{~km}$ height resolution) and $0.5 \mathrm{ppm}$ above $38 \mathrm{~km}(7-8 \mathrm{~km}$ height resolution) when spectroscopic uncertainties are taken into account. The total random error for single profiles (total error without spectroscopic error contribution) improves above $17 \mathrm{~km}$ because there the parameter error is dominated by spectroscopic uncertainties rather than by random components (Fig. 4). The total random error for a single HDO profile is between $3.30 \mathrm{ppb}$ at $11 \mathrm{~km}$ and $0.15 \mathrm{ppb}$ at $22 \mathrm{~km}$. For $\mathrm{H}_{2} \mathrm{O}$ the range is $4.79 \mathrm{ppm}(11 \mathrm{~km})$ to $0.20 \mathrm{ppm}(37 \mathrm{~km})$.
At most of the altitudes it is approximately $0.20 \mathrm{ppm}$. The reduction of the random error with altitude is stronger for the $\mathrm{H}_{2} \mathrm{O}$ profiles, because the HDO measurements carry more noise. We note that the errors reported here are not the limit for the conventional retrieval of $\mathrm{H}_{2} \mathrm{O}$, but the precision is artificially reduced due to the chosen altitude resolution. Dedicated water retrievals achieve better results (Milz et al., 2005).

\section{Isotope fractionation}

\subsection{From HDO measurements to $\delta \mathrm{D}$ values}

The target quantity for isotope assessment is the heavy-tolight isotopic ratio $R$ of a sample. In our case $R=[\mathrm{D}] /[\mathrm{H}]$. The brackets indicate that we refer to vmr. For quantifying heavy isotope abundances, this ratio is usually compared to a standard ratio in the common $\delta$ notation

$\delta \mathrm{D}=\left(\frac{R}{R_{\mathrm{VSMOW}}}-1\right) \times 1000 \%$ 。

where VSMOW stands for the international standard material Vienna Standard Mean Ocean Water $\left(\mathrm{R}_{\mathrm{VSMOW}}=155.76 \times 10^{-6}\right)$. Rather than the atomic $\mathrm{D} / \mathrm{H}$ ratio, our optical measurements return the molecular abun- 
dances of $\mathrm{HDO}$ and $\mathrm{H}_{2} \mathrm{O}$. A modified $\delta$ value can be defined for the molecular ratio $R^{\mathrm{HDO}}=[\mathrm{HDO}] /\left[\mathrm{H}_{2} \mathrm{O}\right]$ as

$\delta \mathrm{HDO}=\left(\frac{R^{\mathrm{HDO}}}{R_{\mathrm{VSMOW}}^{\mathrm{HDO}}}-1\right) \times 1000$

but in practise these molecular $\delta$ values are very similar to the atomic values. As the abundance of double deuterated water molecules is negligible small and the fraction $\mathrm{H}$ in HDO relative to $\mathrm{H}_{2} \mathrm{O}$ is also negligible for our purposes, we can approximate

$$
\frac{[\mathrm{D}]}{[\mathrm{H}]}=\frac{[\mathrm{HDO}]+2[\mathrm{DDO}]}{2\left[\mathrm{H}_{2} \mathrm{O}\right]+[\mathrm{HDO}]} \approx \frac{[\mathrm{HDO}]}{2\left[\mathrm{H}_{2} \mathrm{O}\right]} .
$$

Because of its low abundance in the order of ppb, HDO is a highly challenging target for remote sensing systems and it is mandatory to closely look at the accuracy of the final data. Thus, it is necessary to provide error estimates for the individual species as well as for $\delta \mathrm{D}$. A ratio profile $\boldsymbol{q}^{\mathrm{HDO}}$ is a vector of the shape

$\boldsymbol{q}^{\mathrm{HDO}}=\left(\frac{[\mathrm{HDO}]_{1}}{\left[\mathrm{H}_{2} \mathrm{O}\right]_{1}}, \ldots, \frac{[\mathrm{HDO}]_{i}}{\left[\mathrm{H}_{2} \mathrm{O}\right]_{i}}, \ldots, \frac{[\mathrm{HDO}]_{n}}{\left[\mathrm{H}_{2} \mathrm{O}\right]_{n}}\right)^{T}$.

where the subscripts indicate altitudes. Using Eq. (9) and $\delta \mathrm{D} \approx \delta \mathrm{HDO}$, this can be rewritten in terms of $\delta$ values, since

$$
\frac{[\mathrm{HDO}]}{\left[\mathrm{H}_{2} \mathrm{O}\right]} \approx R_{\mathrm{VSMOW}}^{\mathrm{HDO}}(\delta \mathrm{D}+1) \approx 311.5 \times 10^{-6}(\delta \mathrm{D}+1)
$$

Thus, our measurements can easily be translated to common isotope notation and a profile of $\delta_{i} \mathrm{D}$ values is derived. Figure $5 \mathrm{a}$ shows a typical $\delta \mathrm{D}$ profile inferred from the above described $\mathrm{HDO}$ and $\mathrm{H}_{2} \mathrm{O}$ measurements at $12^{\circ} \mathrm{N}$. The minimum $(-800 \%$ o $)$ is at $\approx 19 \mathrm{~km}$ which is close to the expected entry value of $-650 \%$ o (Moyer et al., 1996) when the total error is taken into account. Above the minimum, $\delta \mathrm{D}$ values increase with altitude.

\subsection{Errors and their propagation in $\delta \mathrm{D}$}

Attempting to detect the natural variability in stratospheric $\delta \mathrm{D}$ requires the assessment of the precision of the single $\mathrm{HDO}$ and $\mathrm{H}_{2} \mathrm{O}$ profiles. The resulting precision for the $\delta \mathrm{D}$ values has to be inferred from the combined errors of the $\mathrm{H}_{2} \mathrm{O}$ and $\mathrm{HDO}$ profiles. Linear error analysis requires linearization of the ratio term in Eq. (9). The dependence of $\delta_{i} \mathrm{D}$ on $[\mathrm{HDO}]_{i}$ is $\left(f=3.2 \times 10^{6} \approx 1000 \times 2 \times \frac{1}{R_{\text {VSMOW }}}\right)$

$\left(\mathbf{J}_{\delta \mathrm{D}, \mathrm{HDO}}\right)_{i, i}=f \times \frac{\partial[\delta \mathrm{D}]_{i}}{\partial[\mathrm{HDO}]_{i}}=f \times \frac{1}{\left[\mathrm{H}_{2} \mathrm{O}\right]_{i}}$,

and the dependence of $\delta_{i} \mathrm{D}$ on $\left[\mathrm{H}_{2} \mathrm{O}\right]_{i}$ is

$\left(\mathbf{J}_{\delta \mathrm{D}, \mathrm{H}_{2} \mathrm{O}}\right)_{i, i}=f \times \frac{\partial[\delta \mathrm{D}]_{i}}{\partial\left[\mathrm{H}_{2} \mathrm{O}\right]_{i}}=f \times \frac{-[\mathrm{HDO}]_{i}}{\left[\mathrm{H}_{2} \mathrm{O}\right]_{i}^{2}}$

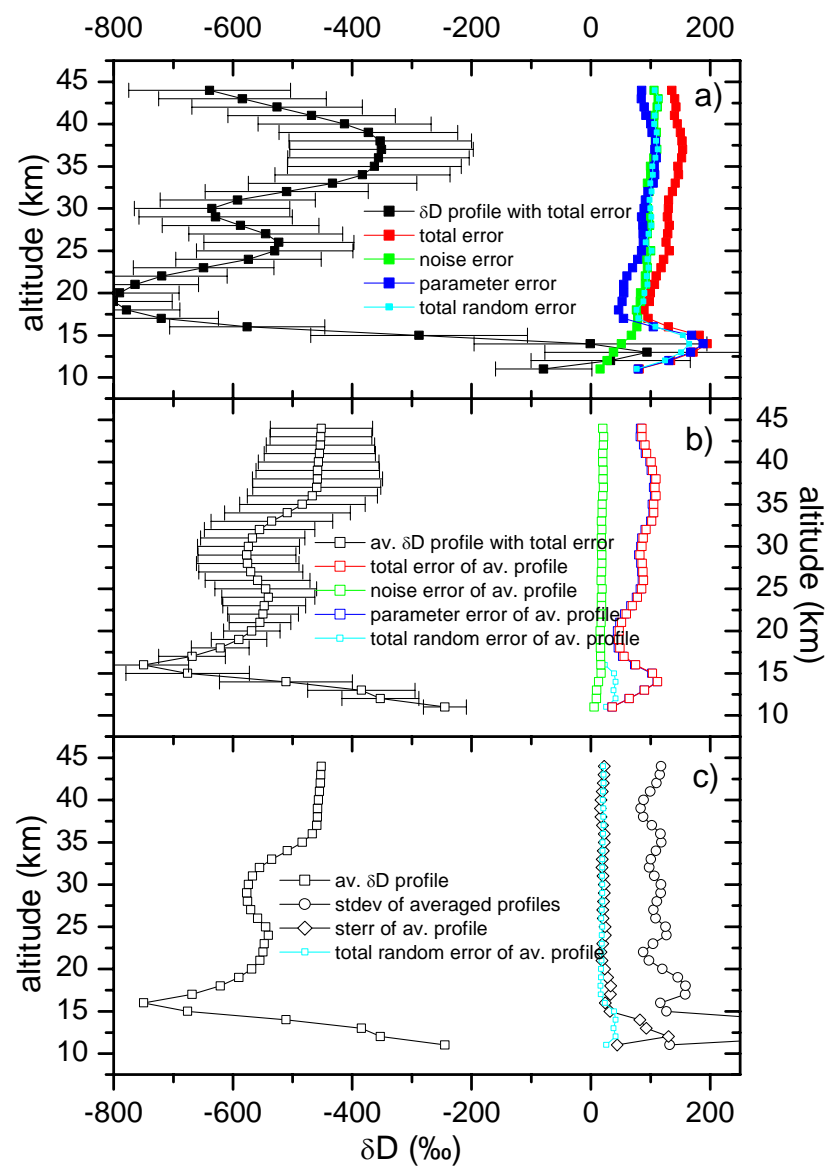

Fig. 5. (a) (top) $\delta \mathrm{D}$ profile retrieved from MIPAS spectra measured on 13 January 2003 at $12^{\circ} \mathrm{N}$ and $28^{\circ} \mathrm{W}$ together with total error bars, noise errors, parameter errors and total random errors. (b) (middle) Zonal mean $\left(7.5^{\circ} \mathrm{N}-12.5^{\circ} \mathrm{N}\right) \delta \mathrm{D}$ profile on 13 January 2003 with estimated errors. (c) (bottom) Averaged delta $\mathrm{D}$ profile with standard deviation and standard deviation of the zonal mean.

The linearization around the retrieved profile $\boldsymbol{x}$ in matrix notation then yields

$$
\begin{aligned}
\left(\delta_{1} \mathrm{D}, \ldots, \delta_{n} \mathrm{D}\right)^{T} & =\mathbf{J} \boldsymbol{x}-\boldsymbol{c} \\
& =\left(\mathbf{J}_{\mathrm{HDO}},-\mathbf{J}_{\mathrm{H}_{2} \mathrm{O}}\right) \times\left(\boldsymbol{x}_{\mathrm{HDO}}, \boldsymbol{x}_{\mathrm{H}_{2} \mathrm{O}}\right)^{T}-\boldsymbol{c},
\end{aligned}
$$

where $\mathbf{J}_{\mathrm{HDO}}$ is a diagonal matrix with $\left(\mathbf{J}_{\delta \mathrm{D}, \mathrm{HDO}}\right)_{i, i}$ along the diagonal, and $\mathbf{J}_{\mathrm{H}_{2} \mathrm{O}}$ with $\left(\mathbf{J}_{\delta \mathrm{D}, \mathrm{H}_{2} \mathrm{O}}\right)_{i, i}$, respectively. $\left(\mathbf{x}_{\mathrm{HDO}}^{T}, \mathbf{x}_{\mathrm{H}_{2} \mathrm{O}}^{T}\right)^{T}$ is the profile vector composed of the profile values $[\mathrm{HDO}]_{i}$ and $\left[\mathrm{H}_{2} \mathrm{O}\right]_{i} . c$ is a vector with $n$ elements where each element has a constant value, $c_{i}=1000$. With the linearization of the ratio available in matrix notation, the error covariance matrix of the $\delta \mathrm{D}$ profile can be written as

$\mathbf{S}_{\delta \mathrm{D}}=\mathbf{J} \mathbf{S}_{\mathrm{x}} \mathbf{J}^{T}$ 


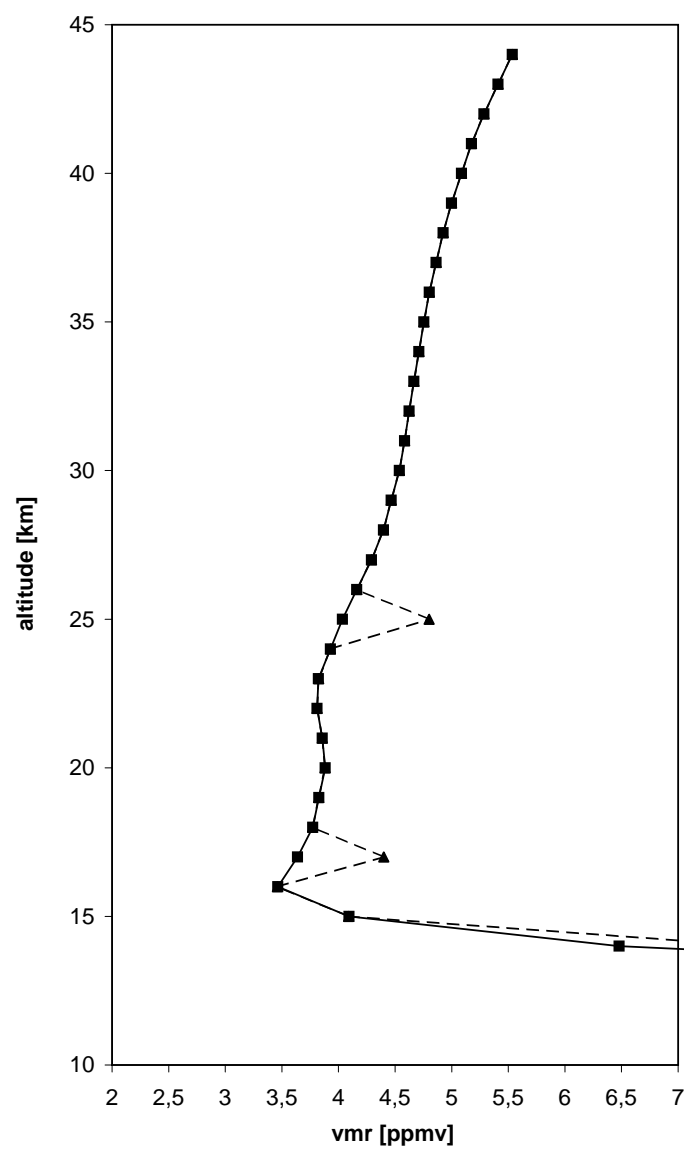

Fig. 6. $\mathrm{H}_{2} \mathrm{O}$ input profile for sensitivity study. We introduced artificial spikes of $+20 \%$ at 14,17 and $25 \mathrm{~km}$ altitude either only to the total water profile (all isotopologues) or to all water isotopologues but HDO (dashed line). The solid line shows the undisturbed water input profile.

where $\mathbf{S}_{\mathrm{x}}$ is the combined covariance matrix of HDO and $\mathrm{H}_{2} \mathrm{O}$

$\mathbf{S}_{\mathrm{x}}=\left(\begin{array}{cc}\mathbf{S}_{\mathrm{HDO}} & \mathbf{C}_{\mathrm{HDO}, \mathrm{H}_{2} \mathrm{O}}^{T} \\ \mathbf{C}_{\mathrm{HDO}, \mathrm{H}_{2} \mathrm{O}} & \mathbf{S}_{\mathrm{H}_{2} \mathrm{O}}\end{array}\right)$

The sub-matrix $\mathbf{C}$ contains the related covariances between $\mathrm{HDO}$ and $\mathrm{H}_{2} \mathrm{O}$. This formulation holds for all types of errors (noise, parameter and smoothing). For the standard deviation $\sigma_{i, \delta \mathrm{D}}$ at altitude level $i$ Eq. (16) gives

$$
\begin{aligned}
\sigma_{i, \delta \mathrm{D}}= & f \times \frac{1}{\left[\mathrm{H}_{2} \mathrm{O}\right]_{i}^{2}} \times\left([\mathrm{HDO}]_{i}^{2} \sigma_{i, \mathrm{H}_{2} \mathrm{O}}^{2}+\left[\mathrm{H}_{2} \mathrm{O}\right]_{i}^{2} \sigma_{i, \mathrm{HDO}}^{2}(18)\right. \\
& \left.-2 r_{\mathrm{HDO}_{i}, \mathrm{H}_{2} \mathrm{O}_{\mathrm{i}}} \sigma_{i, \mathrm{HDO}} \sigma_{i, \mathrm{H}_{2} \mathrm{O}}[\mathrm{HDO}]_{i} \times\left[\mathrm{H}_{2} \mathrm{O}\right]_{i}\right)^{1 / 2},
\end{aligned}
$$

where $r$ is the correlation coefficient of the errors of HDO and $\mathrm{H}_{2} \mathrm{O}$ at altitude $i$.

\subsubsection{Noise error for $\delta \mathrm{D}$}

With the noise retrieval error covariance matrix $\mathbf{S}_{\mathrm{n}}$ available for $\left(\boldsymbol{x}_{\mathrm{HDO}}^{T}, \boldsymbol{x}_{\mathrm{H}_{2} \mathrm{O}}^{T}\right)$, the evaluation of the noise error of $\delta \mathrm{D}$ with Eq. (18) is straightforward. Single profile $\delta$ D noise errors are reported in Fig. 5a. In the error propagation the noise error of the ratio is dominated by the product of the noise error of [HDO] with $\left[\mathrm{H}_{2} \mathrm{O}\right]$. This term is at least one magnitude larger than the other terms. That implies that the noise error of the ratio is dominated by the noise error of HDO, i.e. the relative noise error of HDO maps directly onto the $\delta \mathrm{D}$ profile. Figure 5a shows the contribution of the noise error to the error budget for a single $\delta \mathrm{D}$ profile. The values lie between $15 \%$ ( $(11 \mathrm{~km})$ and $112 \%$ (43 km). At most heights we find values of approximately $90 \%$.

\subsubsection{Parameter error for $\delta \mathrm{D}$}

The contributions of the parameter errors without spectroscopic errors to the error budgets of $\mathrm{HDO}$ and $\mathrm{H}_{2} \mathrm{O}$ are notable (see Figs. 2a and 1a). The positively correlated parts of the parameter errors, i.e. the portion that is not hitmid, of $\mathrm{HDO}$ and $\mathrm{H}_{2} \mathrm{O}$ show a tendency to cancel out when creating the ratio $(r \approx 1$ in Eq. (18)). Thus, the parameter errors of $\delta$ D reduce relatively compared to $\mathrm{HDO}$ and $\mathrm{H}_{2} \mathrm{O}$. The total parameter error for $\delta \mathrm{D}$ is dominated by the spectroscopic uncertainties in $\mathrm{HDO}$ and $\mathrm{H}_{2} \mathrm{O}$. Figure 5a shows that the total parameter error is the main error source for the single $\delta \mathrm{D}$ profiles with values between $46 \%$ o $(18 \mathrm{~km})$ and $188 \%$ o (14 km). Above $18 \mathrm{~km}$ we mostly find values lower than $100 \%$.

\subsubsection{Smoothing error for $\delta \mathrm{D}$}

As outlined in Sect. 4.3, the smoothing error can only be evaluated if a true climatological covariance matrix of the target quantity is known. While the smoothing error caused by the limited altitude resolution often is sufficiently characterized by reporting the altitude resolution of the profile, artifacts in the profile of ratios are a major concern when the two quantities are retrieved with different altitude resolutions.

There are several options to solve or bypass this problem. Ratio profiles can be retrieved directly instead of dividing retrieved mixing ratios (Schneider et al., 2006; Payne et al., 2004). The smoothing error can also be evaluated explicitly using a climatological covariance matrix estimated by the help of a model (Worden et al., 2005).

We have chosen another approach, which is to calculate the ratio of two profiles of nearly the same altitude resolution in order to avoid artifacts in the ratio profile. Using profiles with similar averaging kernels allows us to calculate the ratios without the risk of artifacts and the altitude resolution of the resulting ratio profile is close to equal to that of the original $\mathrm{HDO}$ and $\mathrm{H}_{2} \mathrm{O}$ profiles. This is sufficiently valid for altitudes between 11 and $45 \mathrm{~km}$ (Figs. $3 \mathrm{c}$ and d). 


\subsubsection{Sensitivity study}

To check the validity of the underlying assumptions and approximations, two sensitivity tests were carried out with simulated profiles. As reference profile we used a typical tropical $\mathrm{H}_{2} \mathrm{O}$ profile as shown in Fig. 6 and a corresponding HDO profile that had the isotopic composition of the VSMOW, thus an enrichment of $0 \%$. The corresponding retrieval result is shown in Fig. 7, which shows that for this single profile retrieval we obtain a resulting profile with an average $\delta \mathrm{D}$ value of $-4 \%$ (thus very close to $0 \%$ ) and moderate oscillations smaller than $20 \%$ in the lower stratosphere.

In the first sensitivity test we then added 3 sharp positive $20 \%$ perturbations at 14,17 and $25 \mathrm{~km}$ (see Fig. 6 ) on the total water vapor profile, i.e., for all isotopologues, to the atmosphere used to generate synthetic observations. The retrieval reproduced the higher total water content due to these spikes, but strongly smoothed out the spikes according to the limited altitude resolution (not shown). The isotopic fractionation, however, changed by less than 10\%o (Fig. 7). This result confirms that no significant artifacts in the isotopic fractionation profiles due to smoothing error propagation are to be expected and that the strategy to use equally resolved profiles for ratio calculation is sufficiently robust. This is particularly remarkable considering the fact that the $20 \%$ perturbations applied are large compared to natural total water variations and the $10 \%$ response of inferred $\delta \mathrm{D}$ values is much smaller than the expected and observed $\delta \mathrm{D}$ variations.

In the second sensitivity study we applied the retrieval to perturbations as described above to all water isotopologues except HDO. This implies that the input signal was isotopically strongly depleted at the height levels of the disturbances where $20 \%$ more $\mathrm{H}_{2}^{16} \mathrm{O}$ was artificially added (Fig. 6). The resulting $\delta \mathrm{D}$ profiles (Fig. 7) show a clear response to this perturbation. However, as expected the perturbation is smoothed out according to the actual altitude resolution of the retrieved $\mathrm{HDO}$ and $\mathrm{H}_{2} \mathrm{O}$ profiles. In fact, the two peaks at 14 and $17 \mathrm{~km}$ altitude cannot be resolved with our altitude resolution and are retrieved as one broad structure. On average $\delta \mathrm{D}$ values are decreased by $\approx-50 \%$, which reflects the smoothing of the input of $\approx-200 \% \circ \mathrm{H}_{2}^{16} \mathrm{O}$. On the tail of this broad structure we see the response to the second perturbation at $25 \mathrm{~km}$ altitude, which is clearly resolved by the retrieval. Over the altitude range 10 to $30 \mathrm{~km}$ where we observe a response to the perturbation, the average enrichment is $\approx-35 \%$. This integrated response compares well with the input signal, where $\mathrm{H}_{2}^{16} \mathrm{O}$ was disturbed by $-200 \%$ at 3 out of 21 altitude levels, which corresponds to an average perturbation of $-29 \%$.

\subsection{Total error of $\delta$ D-Profiles}

Figure 5a shows the representative $\delta \mathrm{D}$ profile and the associated errors. At first we note the important contribution of the parameter error: In the $\mathrm{HDO}$ and $\mathrm{H}_{2} \mathrm{O}$ case the parame-

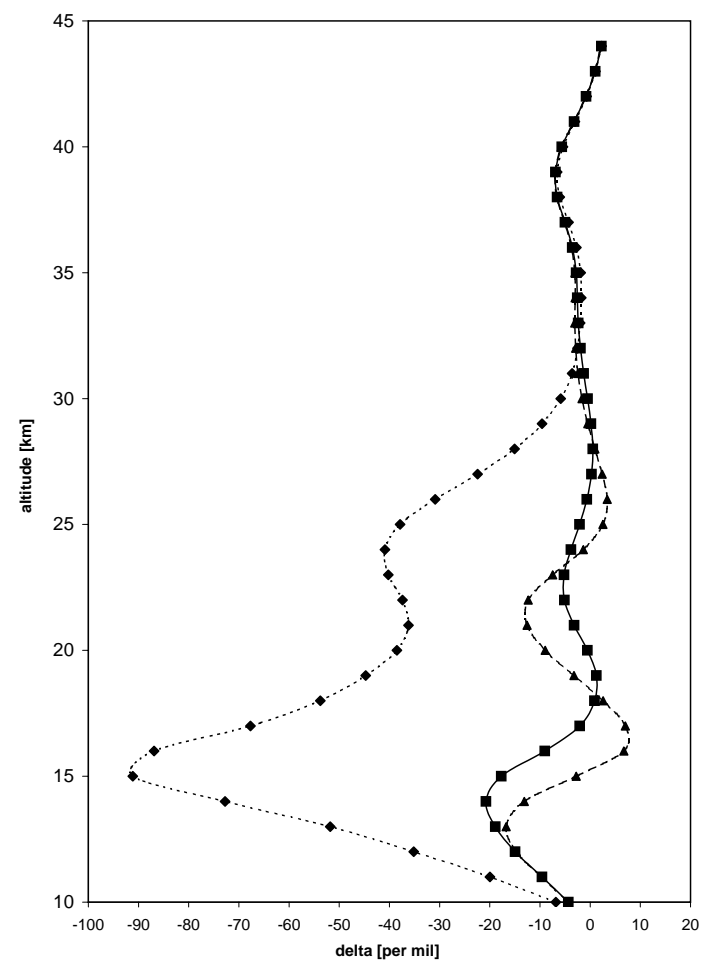

Fig. 7. Inferred $\delta \mathrm{D}$ profiles from the sensitivity study. Sqares, solid line: no perturbation (reference); triangles, dashed line: total water perturbed $(+20 \%$ at 14,17 and $25 \mathrm{~km})$; dots, dotted line: all water isotopes but HDO perturbed $(+20 \%$ at 14,17 and $25 \mathrm{~km})$. When total water is perturbed, the profiles do not deviate substantially. When HDO is perturbed, the total shift in the isotope ratio in the input profile is well recovered by a shift in the $\delta \mathrm{D}$ value that varies with height. Perturbation spikes are smeared out due to the limited vertical resolution.

ter error had a share of $\approx 20$ to $30 \%$. In the $\delta \mathrm{D}$ case this is very similar which is a consequence of the strong influence of the uncorrelated spectroscopic errors of $\mathrm{HDO}$ and $\mathrm{H}_{2} \mathrm{O}$. Thus, we obtain a height dependent total parameter error profile with values between 46 and $188 \%$. The noise error has a magnitude of 15 to $112 \%$. Together this leads to a height dependent total error for a single $\delta \mathrm{D}$ profile in the range between $80 \%$ (11 km) and $195 \%$ o $(14 \mathrm{~km})$. Most values are between 90 and $145 \%$.

\section{Averaging}

Envisat performs 14 orbits per day. As longitudinal variability in the stratosphere is generally much smaller than latitudinal variability, we have averaged all $\mathrm{H}_{2} \mathrm{O}$ and $\mathrm{HDO}$ measurements by longitude and calculated daily $\delta \mathrm{D}$ profiles. At each altitude level $i$ the random error of the average, i.e., the noise error and random parts of the parameter error, is reduced by a factor of $1 / \sqrt{N_{i}}$, where $N_{i}$ is the number of profile values 
Table 3. Number of measurements per height step taken into account for averaging, for the measurements on 13 January 2003 between $7.5^{\circ} \mathrm{N}$ and $12.5^{\circ} \mathrm{N}$.

\begin{tabular}{cc}
\hline Altitude(s) $[\mathrm{km}]$ & Number of measurements \\
\hline 11 & 9 \\
12 & 9 \\
13 & 15 \\
14 & 16 \\
15 & 16 \\
16 & 18 \\
17 & 22 \\
18 & 23 \\
19 & 26 \\
$20-44$ & 28 \\
\hline
\end{tabular}

at altitude $i$ which were actually used for averaging. The retrieval algorithm identifies problematic measurements, e.g., measurements affected by clouds, and excludes them from the ongoing calculation. This leads to the altitude dependence of $N_{i}$ as shown in Table 3 .

From Figs. $2 b$ and $1 b$ the estimated reduction of the total error due to averaging is visible for the representative individual $\mathrm{HDO}$ and $\mathrm{H}_{2} \mathrm{O}$ profiles. In the lower stratosphere below $20 \mathrm{~km}$ random errors dominate the error budget for both species and averaging leads to a strong improvement in the total error. In the case of $\mathrm{H}_{2} \mathrm{O}$, above $20 \mathrm{~km}$ the parameter error components dominate the error profile and averaging leads to marginal improvement of the total error only. For HDO, the random errors are still the most important part of the error in this region, and the total error is strongly reduced by the averaging. After averaging, the total random errors are only dominating below $15 \mathrm{~km}$, thus further averaging will not significantly reduce the errors at higher altitudes. Here the improvement of the spectroscopic uncertainty portion of the parameter error is the key to improving the total error.

The theoretically derived errors as estimated above ("estimated errors") are compared to the actually derived variability of averaged $\mathrm{HDO}$ and $\mathrm{H}_{2} \mathrm{O}$ profiles, quantified in terms of the standard deviation of the ensemble

$\sigma_{\mathrm{ens}, i}=\sqrt{\frac{\sum_{n=1, N_{i}}\left(\boldsymbol{x}_{i, n}-\overline{\boldsymbol{x}}_{i}\right)^{2}}{N_{i}-1}}$.

and standard deviation of the mean

$\sigma_{\text {mean }, i}=\frac{1}{\sqrt{N_{i}}} \sqrt{\frac{\sum_{n=1, N_{i}}\left(\boldsymbol{x}_{i, n}-\overline{\boldsymbol{x}}_{i}\right)^{2}}{N_{i}-1}}$

$i$ is the height index and $N$ denotes the number of the profile values used for averaging. If the retrieved variability was much larger than the estimated error, this would either hint at underestimated errors or large natural variability within the ensemble, for example due to longitudinal variations. The standard deviation and the standard deviation of the mean $\mathrm{H}_{2} \mathrm{O}$ and $\mathrm{HDO}$ profiles are shown in Figs. 1c and 2c. The magnitude of the standard deviation of the mean is in good agreement with the random component of the estimated total error of the averaged profiles, with the exception of the two lowest altitudes (Figs. 1b and 2b). Using Eq. (19) we also calculated the standard deviation of the ensemble for $\delta \mathrm{D}$ (Fig. 5c). Again, the good agreement between the theoretically estimated total error (Fig. 5a) and the standard deviation of the ensemble shows that the error estimation is sufficiently conservative and that the ensemble variability is small enough for meaningful averaging.

\subsection{Latitudinal and vertical distribution of $\mathrm{H}_{2} \mathrm{O}$}

In the zonal mean, water shows the expected distribution that has been established in numerous studies carried out in the past (e.g. (Randel et al., 2001)): For 13 January 2003 we observe values $>100 \mathrm{ppm}$ in the troposphere, which decrease rapidly towards the tropopause (Fig. 8) due to decreasing temperatures. Values between 3 and 5 ppm are observed in the tropopause region and lower stratosphere (Fig. 8) and the minimum is located at the tropical tropopause of the winter hemisphere. A secondary minimum at around $23 \mathrm{~km}$ in the tropical stratosphere indicates the upward propagation of the seasonal cycle as part of the atmospheric tape recorder effect (Mote et al., 1996). In the stratosphere, $\mathrm{H}_{2} \mathrm{O}$ levels increase again with increasing altitude and latitude up to values of about $7.5 \mathrm{ppm}$ at the top of the shown height range. This shows the in situ production of $\mathrm{H}_{2} \mathrm{O}$ from $\mathrm{CH}_{4}$ oxidation, which increases as air ages in the stratospheric circulation. In the cold Arctic winter vortex, we observe air from higher altitudes with high water content descending into the stratosphere down to $25 \mathrm{~km}$. Deviations of our averaged water profiles retrieved with limited vertical resolution from validated water retrievals of better altitude resolution (Milz et al., 2005) do generally not exceed $1 \mathrm{ppm}$ when looking at annual averages. Occasionally, larger differences (up to $2 \mathrm{ppm}$ ) occur at the tropopause. In the present case there is such a feature at $10^{\circ} \mathrm{S}$. However, close to the tropopause larger deviations are expected due to strong vertical gradients both in $\mathrm{H}_{2} \mathrm{O}$ and $\mathrm{HDO}$ there. Also, the artificially reduced height resolution of our $\mathrm{H}_{2} \mathrm{O}$ retrievals (to match the altitude resolution of HDO) compared to Milz et al. (2005) influences the quality of the results. Thus, these deviations are intrinsic to our retrieval approach.

For the day of our retrieval, the retrieved profiles suggest a sharp hygropause, particularly in the region around $65^{\circ} \mathrm{S}$. Such a sharp hygropause cannot be resolved by MIPAS, and it leads to oscillations above the hygropause which produce an artificial $\mathrm{H}_{2} \mathrm{O}$ minimum there. Those oscillations also lead to unusually high variability in this region, and indeed the standard deviation shows a pronounced maximum there. Therefore, this structure is excluded from further examination. 


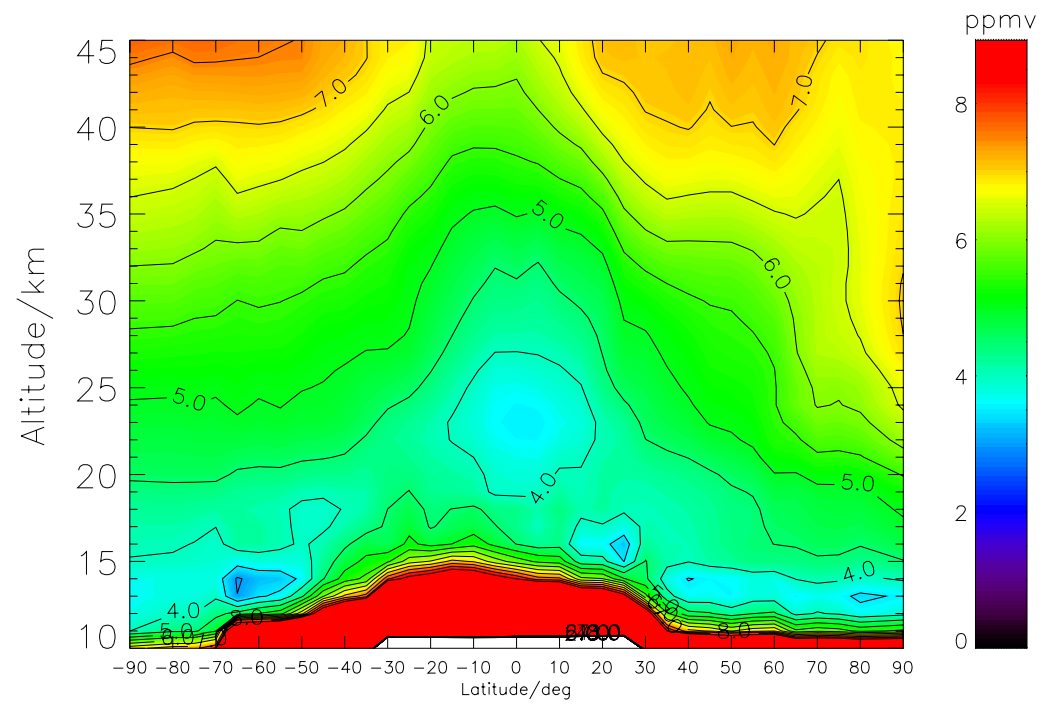

Fig. 8. Zonal mean distribution of $\mathrm{H}_{2} \mathrm{O} 13$ January 2003, measured by MIPAS. 9 to 28 measurements were taken into account for averaging at each altitude and latitude level (see Table 3 for details).

\subsection{Latitudinal and vertical distribution of HDO}

Figure 9 shows the zonal mean distribution of HDO on 13 January 2003. The general distribution of HDO, i.e., its increase above the tropopause as well as the general latitudinal shape, is similar to that of $\mathrm{H}_{2} \mathrm{O}$, which reflects the fact that both species have a common in situ source in the stratosphere i.e. oxidation of $\mathrm{CH}_{4}$ and $\mathrm{H}_{2}$. The $\mathrm{HDO}$ minimum at the northern tropical tropopause corresponds to the $\mathrm{H}_{2} \mathrm{O}$ minimum with values of approximately $0.2 \mathrm{ppb}$. Corresponding to $\mathrm{H}_{2} \mathrm{O}$ we observe a secondary minimum in the tropical stratosphere around $23 \mathrm{~km}$ also for HDO. The descent of air in the winter vortex is amplified in $\mathrm{HDO}$ compared to $\mathrm{H}_{2} \mathrm{O}$, because the descending water is strongly enriched in deuterium. As a general characteristic, the HDO contours are less smooth than those of $\mathrm{H}_{2} \mathrm{O}$. As noted for $\mathrm{H}_{2} \mathrm{O}$, the $\mathrm{HDO}$ minimum at $60-70^{\circ} \mathrm{S}$ and $13 \mathrm{~km}$ altitude is caused by the sharp retrieved hygropause and is not statistically significant. The standard deviation of the negative HDO values reach up to $250 \%$ in this region. This negative artifact causes a positive compensating feature in the layer above at $15-17 \mathrm{~km}$ altitude.

\subsection{Latitudinal and vertical distribution of $\delta \mathrm{D}$}

The $\delta \mathrm{D}$ value quantifies the ratio of $\mathrm{HDO}$ and $\mathrm{H}_{2} \mathrm{O}$ and it therefore highlights the differences in the general behavior of the two species. If changes in HDO perfectly mirrored changes in $\mathrm{H}_{2} \mathrm{O}$ in the stratosphere, Fig. 10 would show constant values throughout the stratosphere. However, we observe an increase in $\delta \mathrm{D}$ with altitude above the tropopause and with latitude, thus as water increases it also gets isotopically enriched. This shows directly that $\mathrm{H}_{2} \mathrm{O}$ derived from the oxidation of $\mathrm{CH}_{4}$ and $\mathrm{H}_{2}$ is isotopically enriched relative to the $\mathrm{H}_{2} \mathrm{O}$ that is injected from the troposphere, in agreement with the expectations and with results from earlier measurement and model results (Moyer et al., 1996; Zahn et al., 2006; Johnson et al., 2001a; Stowasser et al., 1999; Rinsland et al., 1991). However, here for the first time we see a full two dimensional plot of $\delta \mathrm{D}$ in the stratosphere. The data indicate lower near tropopause $\delta \mathrm{D}$ values in the winter hemisphere compared to the summer hemisphere, from the tropics to the high latitudes (with the exception of the artificial structure at $60-70^{\circ} \mathrm{S}$ ). A detailed scientific interpretation of all those structures will follow in a dedicated publication.

In this paper we have shown that the natural variations in stratospheric $\delta \mathrm{D}$ values can be clearly resolved because they are larger than the total errors derived above. As shown in Fig. $5 \mathrm{~b}$, the estimated total error of an averaged $\delta \mathrm{D}$ profile reduces to values between $35 \%$ ( $11 \mathrm{~km})$ and $110 \%$ ( $36 \mathrm{~km})$ when the noise part of the total error has been reduced by a factor of $1 / \sqrt{N_{i}}$. Most values are around $80 \%$. The estimated total random error for the averaged $\delta \mathrm{D}$ profiles is below $42 \%$ of all heights with a minimum of $16 \%$ ( $18 \mathrm{~km})$ and a maximum of $41 \%$ ( $14 \mathrm{~km})$. In comparison, the natural variations recorded in the MIPAS data span several hundred \%o.

The MIPAS measurements thus provide a unique data set that will enable us to study various parts of the stratospheric water cycle in unprecedented detail. Because of the limited vertical resolution we are not able to resolve individual small scale processes $(<4 \mathrm{~km})$ like convective updraft that might also affect the isotopic fractionation of water in the stratosphere (Webster and Heymsfield, 2003). However, their large scale relevance may well be assessed, and for the global stratospheric water cycle, this may even be the more important information. 


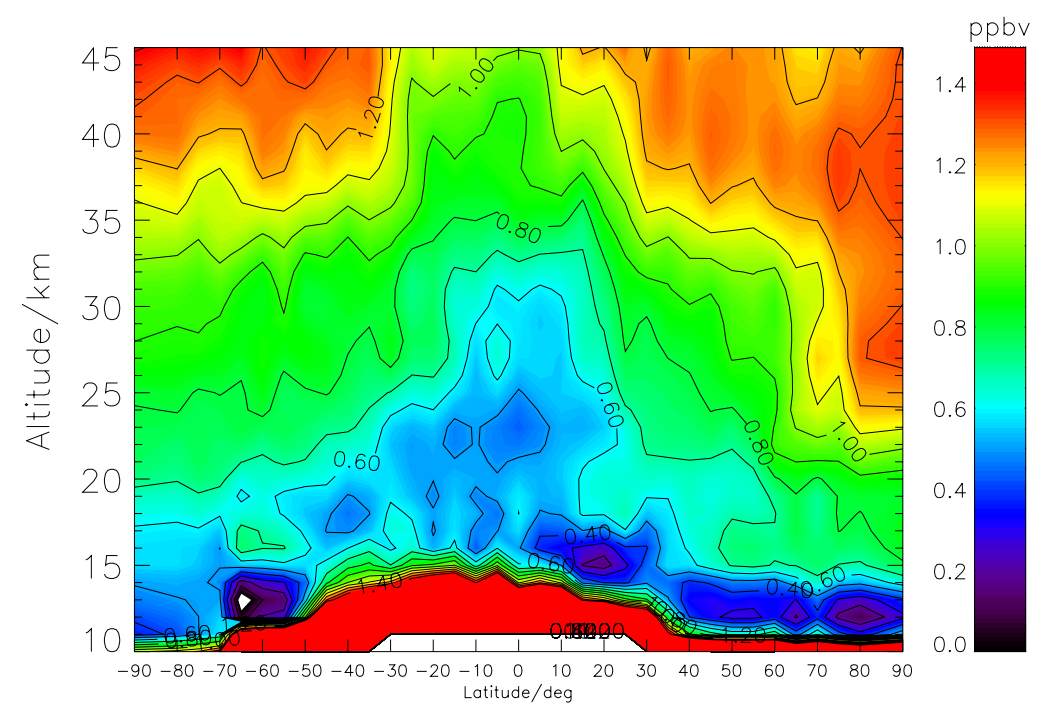

Fig. 9. Zonal mean distribution of HDO for 13 January 2003, measured by MIPAS, 9 to 28 measurements were taken into account for averaging at each altitude and latitude level (see Table 3 for details).

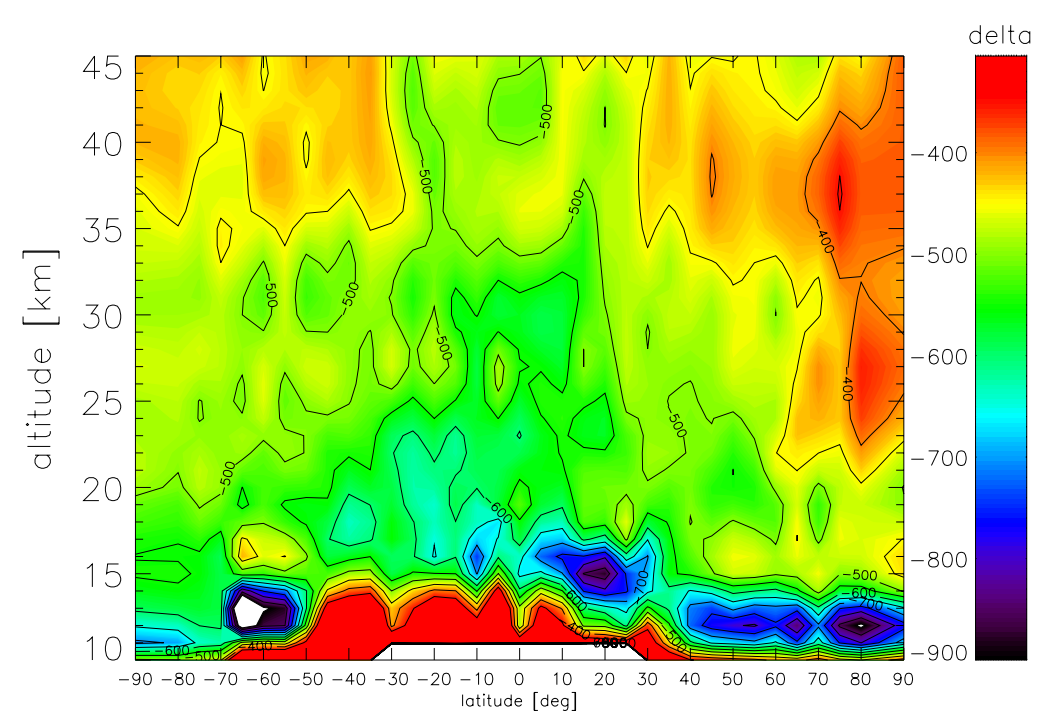

Fig. 10. Zonal mean distribution of $\delta \mathrm{D}, 13$ January 2003, inferred from averaged $\mathrm{HDO}$ and $\mathrm{H}_{2} \mathrm{O}$ measurements by MIPAS.

\subsubsection{Comparison to other data sets}

Figure 11 shows a comparison of our MIPAS retrievals to published values from the literature (Rinsland et al., 1991; Kuang et al., 2003; Johnson et al., 2001a; Dinelli et al., 1991, 1997). The general trends in the stratosphere from the earlier studies are captured by the MIPAS data. Perfect agreement cannot be expected, because

1. our profile was actually taken in the tropics with colder tropopause temperatures compared to the Johnson et al. (2001a) data that were obtained at $33^{\circ} \mathrm{N}$ and the Rins- land et al. (1991) data obtained at $30^{\circ} \mathrm{N}$ and $47^{\circ} \mathrm{N}$; The Dinelli data were taken at $32^{\circ} \mathrm{N}$ (Dinelli et al., 1991) and $34^{\circ} \mathrm{N}$ (Dinelli et al., 1997);

2. the earlier recorded profiles were obtained at different times of the year and differences could be due to a possible seasonal effect and

3. near the tropopause both $\mathrm{HDO}$ and $\mathrm{H}_{2} \mathrm{O}$ have strong gradients, which can potentially cause averaging problems when the vertical resolution is limited. 

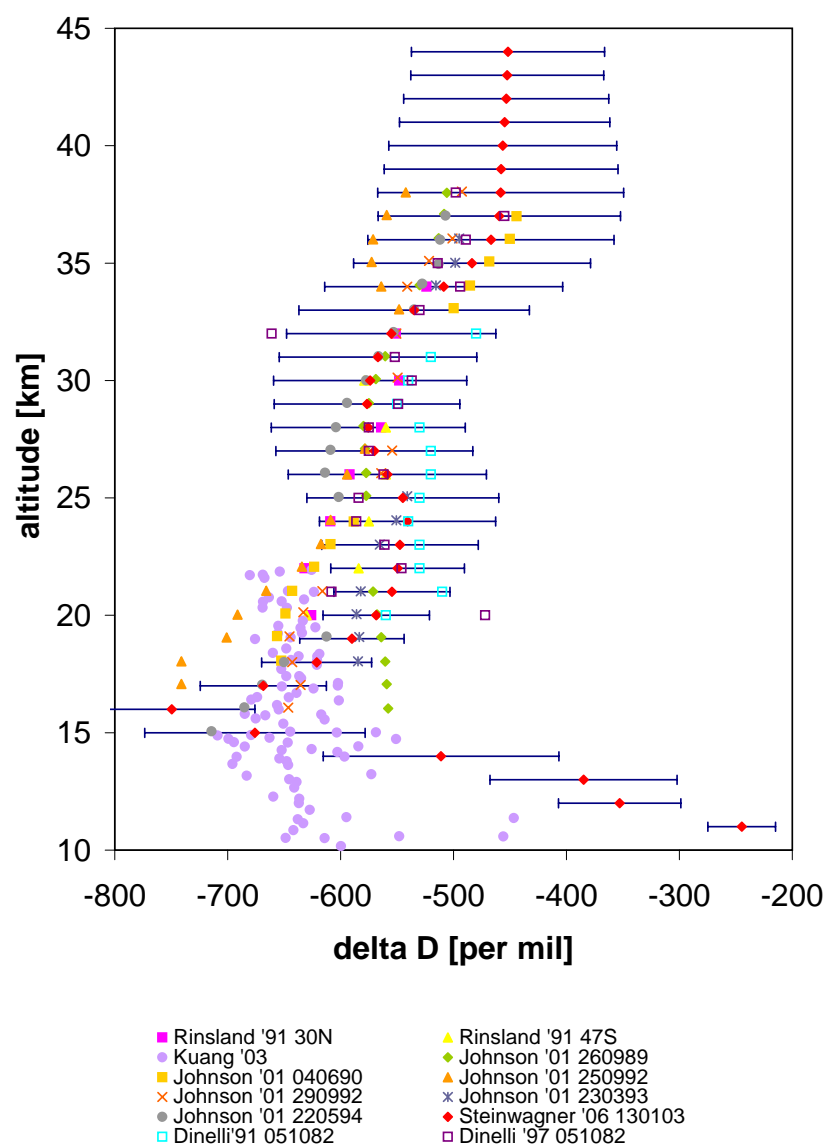

Rinsland '91 47S - Johnson '01 260989 A Johnson '01 250992 * Johnson '01 230393 - Steinwagner '06 130103

Fig. 11. Comparison of our results from the MIPAS measurements on 13 January 2003 at $12^{\circ} \mathrm{N}$ and $28^{\circ} \mathrm{W}$ (red dots with total error bars) with measurements by Johnson et al. (2001a), Rinsland et al. (1991), Kuang et al. (2003), Dinelli et al. (1991) and Dinelli et al. (1997). The MIPAS profile shows the averages from 9 to 28 measurements per altitude level (Table 3) on 13 January 2003. Note that the different data sets were obtained in different seasons and at different latitudes.

Below the tropopause, our $\delta \mathrm{D}$ values are more enriched than most of the Kuang et al. (2003) data. However, large variability in the upper troposphere was recently reported from in situ measurements (Webster and Heymsfield, 2003). Overall, the vertical structure, in particular the increase of $\delta \mathrm{D}$ with altitude above the point of minimum temperature, is in good agreement with the available data.

\section{Conclusions}

We have shown that MIPAS limb emission spectra can be used to investigate the isotopic composition of water vapor in the stratosphere on a global scale. $\mathrm{HDO}$ and $\mathrm{H}_{2} \mathrm{O}$ profiles are retrieved in a multi target retrieval using the microwindow approach. In order to avoid artifacts in the resulting $\delta \mathrm{D}$ profiles both $\mathrm{HDO}$ and $\mathrm{H}_{2} \mathrm{O}$ are retrieved at the same alti-

tude resolution. A thorough error analysis is carried out to evaluate and distinguish noise and parameter errors. In the $\mathrm{HDO} / \mathrm{H}_{2} \mathrm{O}$ ratio a considerable fraction of the parameter error cancels out, and the resulting $\delta \mathrm{D}$ profiles are dominated by spectroscopic uncertainties, resulting in a total error for single profiles of the order of $80 \%$ ( $(11 \mathrm{~km})$ to $195 \%$ o (14 km) with most values between 90 and $145 \%$. The random component of the estimated total error can strongly be reduced by taking averages over multiple orbits on a single day. Thus, random errors are no longer limiting the measurement precision for one day averaging. The estimated total error of the averaged profiles (including spectroscopic uncertainties) is between $35 \%$ ( $11 \mathrm{~km})$ and $110 \%$ o $(36 \mathrm{~km})$. The random component of the total error is below $42 \%$ at all heights. The precision and altitude resolution of these zonal mean profiles is sufficient to study fractionation processes on a large scale, e.g. the principle role of different stratospheric dehydration mechanisms, or in situ formation from methane oxidation. Thus the MIPAS measurements will provide unique information about the stratospheric water cycle.

Acknowledgements. This work was carried out as part of the AFO2000 project ISOSTRAT (07ATC01) funded by the German Ministry for Education and Research (BMBF). We thank ESA for access to the data.

Edited by: P. Hartogh

\section{References}

Carlotti, M.: Global-fit approach to the analysis of limb-scanning atmospheric measurements, Appl. Opt., 27, 3250-3254, 1988.

Coffey, M. T., Hannigan, J., and Goldman, A.: Observations of upper troposheric/lower stratospheric water vapor and its isotopes, J. Geophys. Res., 111, D14313, doi:10.1029/2005JD006093, 2006.

Dessler, A. E. and Sherwood, S. C.: A model of HDO in the tropical tropopause layer, Atmos. Chem. Phys., 3, 2173-2181, 2003, http://www.atmos-chem-phys.net/3/2173/2003/.

Dinelli, B. M., Carli, B., and Carlotti, M.: Measurement of Stratospheric Distributions of H216O, H218O, H217O, and HD16O, from Far Infrared Spectra, J. Geophys. Res., 96, 7509-7514, 1991.

Dinelli, B. M., Lepri, G., Carlotti, M., Carli, B., Mencaraglia, F., Ridolfi, M., Nolt, I. G., Ade, P. A. R.: Measurement of the isotopic ratio distribution of $\mathrm{HD} 16 \mathrm{O}$ and $\mathrm{H} 216 \mathrm{O}$ in the $20-38 \mathrm{~km}$ altitude range from far-infrared spectra, Geophys. Res. Lett., 24 , 2003-2006, 1997

Echle, G., von Clarmann, T., Dudhia, A., Flaud, J.-M., Funke, B., Glatthor, N., Kerridge, B., Lopez-Puertas, M., Martý'n-Torres, F. J., and Stiller, G. P.: Optimized Spectral Microwindows for Data Analysis of the Michelson Interferometer for Passive Atmospheric Sounding on the Environmental Satellite, Appl. Opt., 39, 30, 5531-5540, 2000.

Fischer, H., Blom, C., Oelhaf, H., Carli, B., Carlotti, M., Delbouille, L., Ehhalt, D., Flaud, J.-M., Isaksen, I., Lopez-Puertas, M., McElroy, C. T., and Zander, R.: Envisat-Mipas, the Michel- 
son Interferometer for Passive Atmospheric Sounding; An instrument for atmospheric chemistry and climate research, ESA SP1229, edited by: Readings, C. and Harris, R. A., European Space Agency, Noordwijk, The Netherlands, 2000.

Fischer, H.: Remote Sensing of Atmospheric Trace Gases, Interdisciplinary Science Reviews, 18, 185-191, 1993.

Flaud, J.-M., Piccolo, C., Carli, B., Perrin, A., Coudert, L. H., Teffo, J.-L., and Brown, L. R.: Molecular line parameters for the MIPAS (Michelson Interferometer for Passive Atmospheric Sounding) experiment, Atmos. Oceanic Opt., 16, 172-182, 2003.

Franz, P. and Röckmann, T.: High-precision isotope measurements of $\mathrm{H}_{2}^{16} \mathrm{O}, \mathrm{H}_{2}^{17} \mathrm{O}, \mathrm{H}_{2}^{18} \mathrm{O}$, and the D17O-anomaly of water vapor in the southern lowermost stratosphere, Atmos. Chem. Phys., 5, 2949-2959, 2005,

http://www.atmos-chem-phys.net/5/2949/2005/.

Füglistaler, S. and Haynes, P. H.: Control of interannual and longerterm variability of stratospheric water vapor, J. Geophys. Res., 110, D24108, doi:10.1029/2005JD006019, 2005.

Holton, J. R. and Gettelmann, A.: Horizontal transport and the dehydration of the stratosphere, Geophys. Res. Lett., 28(14), 27992802, 2001.

Irion, F. W., Moyer, E. J., Gunson, M. R., Rinsland, C. P., Michelson, H. A., Salawitch, R. J., Yung, Y. L., Chang, A. Y., Newchurch, M. J., Abbas, M. M., Abrams, M. C., and Zander, R.: Stratospheric observations of $\mathrm{CH}_{3} \mathrm{D}$ and HDO from ATMOS infrared solar spectra: Enrichments of deuterium in methane and implications for HD, Geophys. Res. Lett., 23, 2381-2384, 1996.

Johnson, D. G., Jucks, K. W., Traub, W. A., and Chance, K. V.: Isotopic composition of stratospheric water vapor: Implications for transport, J. Geophys. Res., 106(D11), 12 219-12 226, $2001 \mathrm{a}$.

Johnson, D. G., Jucks, K. W., Traub, W. A., and Chance, K. V.: Isotopic composition of stratospheric water vapor: Measurements and photochemistry, J. Geophys. Res., 106(D11), 12 211-12 217, 2001b.

Kuang, Z., G. C, T., Wenneberg, P. O., and Yung, Y. L.: Measured $\mathrm{HDO} / \mathrm{H}_{2} \mathrm{O}$ ratios across the tropical tropopause, Geophys. Res. Lett., 30(7), 1372, doi:10.1029/2003GL017023, 2003.

Lautie, N., Urban, J., and Group, O. R.: Odin/SMR limb observations of stratospheric water vapor and its isotopes, EGS AGU - EUG Joint Assembly, Abstracts from the meeting held in Nice, France, 6-11 April 2003, abstract \#7320, pp. 7320, http://adsabs.harvard.edu/abs/2003EAEJA.....7320L, 2003.

Milz, M., von Clarmann, T., Fischer, H., Glatthor, N., Grabowski, U., Höpfner, M., Kellmann, S., Kiefer, M., Linden, A., Mengistu Tsidu, G., Steck, T., Stiller, G. P., Funke, B., López-Puertas, M., and Koukouli, M. E.: Water Vapor Distributions Measured with the Michelson Interferometer for Passive Atmospheric Sounding on board Envisat (MIPAS/Envisat), J. Geophys. Res., 110, D24307, doi:10.1029/2005JD005973, 2005

Mote, P. W., Rosenlof, K., McIntyre, M., Carr, E. S., Gille, J. C., Holton, J. R., Kinnersley, J. S., Pumphrey, H. C., Russell III, J. M. R., and Waters, J. W.: An atmospheric tape recorder: The imprint of tropical tropopause temperatures on stratospheric water vapor, J. Geophys. Res., 101, 2989-4006, 1996.

Moyer, E. J., Irion, F. W., Yung, Y. L., and Gunson, M. R.: ATMOS stratospheric deuterated water and implications for troposherestratosphere transport, Geophys. Res. Lett., 23, 2385-2388, 1996.

Payne, V., Dudhia, A., and Piccolo, C.: Isotopic Measurements of
Water Vapour and Methane from the MIPAS Satellite Instrument, AGU Fall Meeting Abstracts, pp. B733, http://adsabs.harvard. edu/abs/2004AGUFM.A21B0733P, 2004.

Pollock, W., Heidt, L., Lueb, R., and Ehhalt, D.: High-precision isotope measurements of $\mathrm{H} 216 \mathrm{O}, \mathrm{H} 217 \mathrm{O}, \mathrm{H} 218 \mathrm{O}$, and the D17Oanomaly of water vapor in the southern lowermost stratosphere, J. Geophys. Res., 85, 5555-5568, 1980.

Randel, W. J., Wu, F., Gettelman, A., III, J. R., Zawodny, J. M., and Oltmans., S. J.: Seasonal variation of water vapor in the lower stratosphere observed in Halogen Occultation Experiment data, J. Geophys. Res., 106(D13), 14 313-14 325, 2001.

Raspollini, P., Belotti, C., Burgess, A., Carli, B., Carlotti, M., Ceccherini, S., Dinelli, B. M., Dudhia, A., Flaud, J.-M., Funke, B., H(̈)pfner, M., Lopez-Puertas, M., Payne, V., Piccolo, C., Remedios, J. J., Ridolfi, M., and Spang, R.: MIPAS level 2 operational analysis, Atmos. Chem. Phys., 6, 5605-5630, 2006, http://www.atmos-chem-phys.net/6/5605/2006/.

Remedios, J.: Extreme atmospheric constituent profiles for MIPAS, 1999. Proceedings of ESAMS '99 - European Symposium on Atmospheric Measurements from Space, 779-782, 1999.

Rinsland, C. P., Gunson, M. R., Foster, J. C., Toth, R. A., Farmer, C. B., and Zander, R.: Stratospheric profiles of heavy water vapor isotopes and $\mathrm{CH}_{3} \mathrm{D}$ from analysis of the ATMOS Spacelab-3 infrared solar spectra, Geophys. Res. Lett., 96(D1), 1057-1068, 1991.

Rodgers, C. D.: Inverse Methods for Atmospheric Sounding: Theory and Practice, World Scientific, ISBN 981022740X, 256 pages, Oxford, 2000.

Rosenlof, K. H., Chiou, E.-W., Chu, W. P., Johnson, D. G., Kelly, K. K., Michelsen, H. A., Nedoluha, G. E., Remsberg, E. E., Toon, G. C., and McCormick, M. P.: Stratospheric water vapor increases over the past half-century, Geophys. Res. Lett., 28, 1195-1198, doi:10.1029/2000GL012502, 2001.

Rothman, L. S., Barbe, A., Benner, D. C., Brown, L. R., CamyPeyret, C., Carleer, M. R., Chance, K., Clerbaux, C., Dana, V., Devi, V. M., Fayt, A., Flaud, J.-M., Gamche, R. R., Goldman, A., Jacquemart, D., Jucks, K. W., Lafferty, W. J., Mandin, J.-Y., Massie, S. T., Nemtchinov, V., Newnham, D. A., Perrin, A., Rinsland, C. P., Schroeder, J., Smith, K. M., Smith, M. A. H., Tang, K., Toth, R. A., Vander Auwera, J., Varanasi, P., and Yoshino, K.: The HITRAN molecular spectroscopic database: edition of 2000 including updates through 2001, J. Quant. Spectrosc. Radiat. Transfer, 82, 5-44, doi:10.1016/S0022-4073(03)00146-8, 2003.

Schneider, M., Hase, F., and Blumenstock, T.: Ground-based remote sensing of $\mathrm{HDO} / \mathrm{H}_{2} \mathrm{O}$ ratio profiles: Introduction and validation of an innovative retrieval approach, Atmos. Chem. Phys., 6, 4705-4722, 2006, http://www.atmos-chem-phys.net/6/4705/2006/.

Sherwood, S. C. and Dessler, A. E.: On the control of stratospheric humidity, Geophys. Res. Lett., 27(16), 2513-2516, 2000.

Smith, J. A., Ackerman, A. S., Jensen, E. J., and Toon, O. B.: Role of deep convection in establishing the isotopic compsition of water vapor in the tropical transition layer, Geophys. Res. Lett., 33, L06812, doi:10.1029/2005GL024078, 2006.

Stiller, G. P.: The Karlsruhe optimized and precise radiative transfer algorithm (KOPRA), Wissenschaftliche Berichte, FZKA 6487, 2000.

Stowasser, M., Oelhaf, H., Wetzel, G., Friedl-Vallon, F., Maucher, 
G., Seefeldner, N., Trieschmann, O., von Clarmann, T., and Fischer, H.: Simultaneous measurements of $\mathrm{HDO}, \mathrm{H}_{2} \mathrm{O}$ and $\mathrm{CH}_{4}$ with MIPAS-B: Hydrogen budget and indication of dehydration inside the polar vortex, J. Geophys. Res., 104(D16), 19213$19225,1999$.

Tikhonov, A.: On the solution of incorrectly stated problems and a method of regularization, Dokl. Acad. Nauk SSSR, 151, 501504,1963

von Clarmann, T., Glatthor, N., Grabowski, U., Höpfner, M., Kellmann, S., Kiefer, M., Linden, A., Tsidu, G. M., Milz, M., Steck, T., Stiller, G. P., Wang, D. Y., Fischer, H., Funke, B., GilLpez, S., and López-Puertas, M.: Retrieval of temperature and tangent altitude pointing from limb emission spectra recorded from space by the Michelson Interferometer for Passive Atmospheric Sounding (MIPAS), J. Geophys. Res., 108(D23), 4736, doi:10.1029/2003JD003602, 2003.

Webster, C. R. and Heymsfield, A. J.: water isotope ratios D/H, O$18 / \mathrm{O}-16$, O-17/O-16 in and out of cloudsmap dehydration pathways, Science, 302(5651), 1742-1745, 2003.
Worden, J. R., Bowman, K., and Noone, D.: TES Observations of the Isotopic composition of Tropospheric Water Vapor, AGU Fall Meeting Abstracts, pp. C3, 2005.

Zahn, A.: Constraints on 2-way transport across the Arctic tropopause based on O-3, stratospheric tracer (SF6) ages, and water vapor isotope (D, T) tracers, J. Atmos. Chem, 39, $303-$ 325, 2001.

Zahn, A., Barth, V., Pfeilsticker, K., and Platt, U.: Deuterium, oxygen-18, and tritium as tracers for water vapour transport in the lower stratosphere and tropopause region, J. Atmos. Chem, 30, 25-47, 1998.

Zahn, A., Franz, P., Bechtel, C., Grooss, J.-U., and Röckmann, T.: Modelling the budget of middle atmospheric water vapour isotopes, Atmos. Chem. Phys., 6, 2073-2090, 2006, http://www.atmos-chem-phys.net/6/2073/2006/. 